\title{
EL DEBILITAMIENTO DE LA FUERZA SINDICAL EN LA SOCIEDAD 4.0
}

\author{
The weakening of trade union strength in society 4.0
}

Priscila Martín Vales*

Abogada; Universidad de Salamanca, España

\section{RESUMEN}

El uso de las TICs, la descentralización productiva y la globalización, entre otros factores, han conllevado al surgimiento de nuevas formas económicas y, por ende, de relaciones laborales. Llevando aparejado una disminución de efectividad de la acción colectiva en las empresas red y en mayor medida, en aquellas en las que se vislumbran tintes de transnacionalidad. Al igual que ha evolucionado las relaciones laborales, ha de evolucionar la normativa aplicable y, tanto los requisitos, como las formas de realizar la acción colectiva. En virtud de lo cual, es necesaria una reforma o relectura de los Títulos II y III ET, con la finalidad de paliar las limitaciones o deficiencias de aplicación de la acción colectiva en las empresas red, a través de cualquiera de sus formas; subcontratación, unión temporal de empresas, empresas multiservicios, a través de plataformas digitales, entre otras.

Palabras clave: empresas red, acción colectiva, multiservicios, unión temporal de empresas, plataformas digitales.

\section{ABSTRACT}

The use of ICTs, outsourcing and globalisation, among other factors, have entailed the risen-up of new economic models, and thus employment law. This is accompanied by a decrease in the effectiveness of the RED-companies' joint action, particularly for those who detect a hint of transnationality. Employment law must evolve in the same way that professional relationships did. And, with it, the current applicable normative, requirements, and ways of establishing joint action will be expanded. A reform and/or review of II and III ET qualifications is required as a result of the latter being placed in context. This is required to alleviate the limitations and lack of implementation of the joint action of the RED-companies. This includes, among other things, subcontracting, company temporal alliances, and multi-service business via digital platforms.

Keywords: network companies, collective action, multi-services, temporary union of companies, digital platforms.

* Correspondencia a: Priscila Martín Vales. Paseo Francisco Tomás y Valiente, s/n, 37007 Salamanca, España. — priscilamv@ usal.es - https: //orcid.org/0000-0002-3929-1824

Cómo citar: Martín Vales, Priscila. (2021). «El debilitamiento de la fuerza sindical en la sociedad 4.0»; Lan Harremanak, 45, 162-183. (https: //doi.org/10.1387/lan-harremanak.22811).

Recibido: 15 mayo, 2021; aceptado: 22 junio, 2021.

ISSN 1575-7048 - eISSN 2444-5819 / (C) 2020 UPV/EHU

(c) Esta obra está bajo una licencia

Creative Commons Atribución 4.0 Internacional 


\section{Introducción}

Las redes empresariales se pueden considerar como una forma difundida de cooperación en Europa, no solo para las pymes, sino, también para las empresas de rango medio (Krebs, 2017; 127). Sin embargo, dichas empresas en red carecen de herramientas eficaces para garantizar la cooperación efectiva (Krebs, 2017; 137). No obstante, el procedimiento de dejar la red no suele estar tan altamente regulado como la expulsión y salida (Krebs, 2017; 137), de la misma de una de las empresas parte de la red.

Es de notoria relevancia traer a colación la clasificación de la normativa aplicable en las empresas red, de un lado, encontramos la «ley dura", que es la emanada directamente del legislador con fuerza obligacional, y, de otro lado, la «ley blanda", cuyas disposiciones no gozan de carácter vinculante y, en los casos en los que, si posee de tal fuerza vinculante, esta es muy limitada. Siendo ambas complementarias y no necesariamente excluyentes.

En relación con la clasificación anteriormente mencionada podemos diferenciar entre las sanciones "formales», relativas a la inobservancia de las estipulaciones contenidas en la «ley dura», y las sanciones «informales», las cuales se derivan del incumplimiento de lo expuesto en las denominadas «leyes blandas» (Krebs, 2017; 164). La justificación de estas últimas la podemos encontrar en la relación especial que une a las empresas de la red.

Cabe señalar, que la normativa aplicable dentro de la denominada «ley blanda", a nivel internacional, a las propias empresas transnacionales, comprende los Acuerdos Marco Internacionales o Globales y los códigos de conducta. Los Acuerdos Marco Internacionales suponen una de las manifestaciones de la negociación colectiva en las redes mundiales de mayor calado, además de ser su contenido la antesala de posibles cambios normativos. Rojas define este instrumento como aquel

negociado por empresas multinacionales y sindicatos mundiales con la finalidad de establecer estándares mínimos de condiciones básicamente laborales que los firmantes se comprometen a hacer cumplir en todos los países en los que opera y en empresas subcontratadas o proveedoras $(2018 ; 273)$.

No obstante, una de las controversias más relevantes dimanantes de estos instrumentos es la relativa a la legitimación negocial de las Federaciones Sindicales Internacionales que los suscriben, además de la posición desigual, al ser negociados éstos por las Federaciones Sindicales Internacionales, por un lado, y por la multinacional, por otro. Empero, a dichas vicisitudes habría que añadir la falta de medios de control del cumplimiento de los mismos y, por ende, de su eficacia jurídica. 
Por otro lado, podemos definir al código de conducta como un conjunto de reglas dirigidas a influir en el comportamiento interno (Krebs, 2017; 153) de la empresa o red empresarial.

La ausencia de norma que contemple las diferentes estructuras organizativas acaecidas en virtud de los diferentes cambios introducidos en la organización de las relaciones laborales, así como los derivados de la innovación de la técnica, pueden dar lugar a diferentes modalidades de prestación de servicios. Empero, dicha evolución no se ha visto reflejada en los consiguientes cambios normativos. Lo cual ha conllevado a que la actualidad de las vicisitudes de las relaciones laborales y su concreción judicial tenga un cariz netamente discrecional, ya que el juzgador no posee norma en la cual apoyar sus resoluciones.

Con la reforma laboral, operada mediante la Ley 3/2012, se introdujo la preferencia aplicativa a los convenios colectivos de empresa frente a los sectoriales en determinadas materias. Por lo cual, operará lo estipulado en los convenios colectivos sectoriales en lo no regulado por un convenio colectivo de empresa. Trasladando tal situación a las empresas multiservicios, se puede observar la implantación de una serie de mecanismos para reforzar los derechos de las personas trabajadoras, tales como, la subrogación convencional, la incorporación de estas empresas en el ámbito funcional de la negociación colectiva sectorial o el establecimiento de límites o prohibiciones a la contratación (Nieto, 2017; 2), de éstas.

Una de las principales consecuencias negativas que conlleva la discrecionalidad judicial, es la inseguridad jurídica, pudiendo darse resoluciones contradictorias ante supuestos similares. Lo cual, a su vez, ha generado una dificultad añadida en relación con la determinación del verdadero sujeto negociador (Soler, 2021; 2).

Por otro lado, la representación de los trabajadores también ha sufrido distensiones en relación con la designación de estos para ostentar la mayor representatividad exigida para la negociación de un convenio colectivo estatutario.

El resultado de la negociación también se ve influido por idiosincrasia de la estructura organizativa, la cual se ve modulada por el factor de la temporalidad de las relaciones laborales vigentes en la misma. Siendo este factor de temporalidad determinante a la hora de influir en las personas trabajadoras de la empresa en el ejercicio de su derecho sindical, entendido el mismo en su máxima expresión.

Lo cual conduce a la imperiosa necesidad de creación de un convenio colectivo aplicable a todas las empresas vinculadas a una misma cadena de suministro, teniendo todas y cada una de las empresas que forman dicha cadena «intereses contrapuestos tanto en las partes negociadoras como en el propio seno interno de cada una de ellas» (Soler, 2021; 4).

Las nuevas realidades empresariales, por su parte, conllevan una notoria dificultad a la hora de «aplicar la regulación tradicional de las unidades de nego- 
ciación colectiva» (Rojas, 2018; 252). Teniendo su máximo exponente en la subcontratación trasnacional con países con una regulación «menos avanzada» o con un desarrollo menor.

Estas han dado lugar a nuevas concepciones de relaciones laborales, así como a nuevas controversias a superar por parte del legislador y las partes de las mismas -empresa y representantes legales de las personas trabajadoras-, las cuales han de sortear estas nuevas vicisitudes, como, por ejemplo, la limitación del ejercicio a la libertad sindical en su máxima expresión. No obstante, y debido la extensión de dicha problemática nos centraremos en la aplicación de la negociación colectiva, dejando a un lado cuestiones tan fundamentales, como las implicaciones acaecidas en el ejercicio del derecho fundamental a la huelga en los sectores externalizados, y su mayor problemática en el seno de las empresas transnacionales. Por ello, las siguientes líneas se centrarán en los supuestos más relevantes, al humilde criterio de esta autora, de externalización de servicios a través de las empresas red.

\section{La estructura de la red como factor determinante en la negociación colectiva}

Uno de los factores determinantes en el desarrollo de las empresas en red es el grado de dependencia que éstas tienen sobre la misma, en cuanto a su grado de implicación interna (Soler, 2021; 8). Dichas empresas, a su vez, gozan del beneficio de participar en redes que hacen más eficientes la colocación de su producto en el mercado (Soler, 2021;8).

El Tribunal Superior de Justicia de Madrid, en su sentencia de 18 de mayo de 2015 (recurso núm. 197/2015), ya consideró la ampliación de concepto de empresa «hacia fuera» "dando cabida a organizaciones productivas coordinadas estables o temporales, pero relacionadas entre sí por motivos productivos». A diferencia de las estipulaciones normativas, las cuales siguen sin dar un significado contenido en el Real Decreto-Ley 7/2011, de 10 de junio, de medidas urgentes para la reforma de la negociación colectiva y sus sucesivas modificaciones, en relación con los procesos de descentralización productiva, como "pluralidad de empresas vinculadas por razones organizativas o productivas nominativamente identificadas en su ámbito de aplicación». No obstante, el legislador nacional se limitó a establecer los efectos de concurrencia y legitimación de los convenios colectivos no identificando el significado ni la aplicación de la expresión anteriormente mencionada, así como, la tipología de las relaciones que deben acaecer entre tales empresas. Tal inexistencia de norma a aplicar en las empresas en red trae consigo la inexorable dificultad de configurar un soporte jurídico (Soler, 2021; 11). 
Por lo cual, el conocimiento por parte de los representantes de las personas trabajadoras sobre el vínculo que las une a cada empresa miembro de la red o de la cadena de suministro, conlleva a la concreción de las posibles violaciones de lo contenido en los convenios o acuerdos colectivos adoptados. Siendo determinante a la hora de invocar el instrumento a aplicar para tales violaciones.

La integración de en redes verticales produce un desplazamiento de poderes decisorios (Soler, 2021; 12), que han de coordinarse con las demás empresas de la red y sujetas a lo estipulado por la empresa dominante.

En los supuestos en los que la relación que une a las empresas en red vertical deja de ser societaria, pasando a ser contractual, tanto su vinculación como las directrices de la empresa predominante resultan más complejas. Manifestándose su poder de decisión en "un mero transmisor de decisiones operativas» (Soler, 2021 ; 13) de la empresa predominante.

Es de notoria relevancia traer a colación, que tal dependencia económica de las empresas red de la empresa predominante no se produce únicamente en los supuestos de subcontratación, sino que esta puede ser inconstante.

Asimismo, dicha dependencia económica puede ser total o parcial, de manera que no es requisito indispensable vincular toda la actividad ni la totalidad de la plantilla de la empresa. Por lo cual, puede darse el supuesto de que en una misma red realicen su prestación de servicios a favor de ésta, personas trabajadoras de distintas empresas y con diferentes condiciones laborales, lo que dificulta en gran medida el agrupamiento de las mismas como fuerza representativa o sindical en la red empresarial. En los casos en los que tales personas trabajadoras que hayan sido contratadas por una empresa de trabajo temporal y que presten sus servicios en una empresa usuaria, la mayoría de las condiciones laborales de éstas serán las que ostenten aquellas contratadas directamente por la empresa usuaria. En consecuencia, en tales supuestos, la flagrante necesidad de homogenizar los convenios colectivos aplicables o, en su caso, elaborar un convenio colectivo vinculante para todas las empresas de la red, es considerablemente inferior.

Las empresas en red se fundamentan en relaciones no jerárquicas de coordinación empresarial en las que se reconoce la interdependencia (Ruíz, 2018; 15). Esto no quiere decir que su estructura se mantenga estática durante todo el tiempo de la relación entre dichas empresas. Por ello, ésta puede cambiar su estructura jerárquica, pasando de una unión contractual a la constitución de filiales.

En los supuestos en los que la red empresarial se articule como una contrata o subcontrata de obras propia del art. $42 \mathrm{ET}^{1}$, se activarán los mecanismos de coordinación incluidos en dicho precepto.

\footnotetext{
1 En este extremo hay que poner especial atención en las reformas anunciadas por el legislador para dicho precepto.
} 
Ha de tenerse en cuenta que cuando unas empresas deciden constituir una red empresarial, la misma dificulta enormemente la acción sindical de los trabajadores en tal red empresarial, "pudiendo este haber sido incluso trazado como objetivo o, simplemente, una consecuencia concomitante» (Díaz, 2018; 235).

\section{La representación legal de los trabajadores en las redes de empresa}

La red empresarial puede tener como una de sus características la inexistencia jurídica de tales sujetos colectivos empresariales, los cuales actuarían como interlocutores formales (Díaz, 2018; 237).

En relación con la legitimación para negociar un convenio colectivo por parte de la patronal, corresponde a las asociaciones empresariales, cuestión plenamente aceptada. La dificultad aparece en supuestos en los que existe una red empresarial. De manera que, para que tal legitimidad pueda darse,

no es necesario que todas y cada una de las empresas afectadas por el convenio colectivo estén adheridas a la misma, sino que cumplido el porcentaje legalmente exigido se considerará acreditado que las asociaciones empresariales poseen esa capacidad especial para representar a la mayoría de los empresarios afectados por el convenio colectivo y, por esa razón, que el mismo pueda tener la eficacia general prevista en el art. 82.3 ET (Nieto, 2017;14).

Diferente supuesto sería el dimanado de la controversia acaecida por la legitimidad de tales asociaciones para negociar un convenio colectivo estatutario.

En lo que respecta a la legitimación inicial para negociar, el ET contempla la representación suficiente de las asociaciones empresariales en el ámbito del convenio colectivo a negociar, no aplicándose, a diferencia de la representación de las personas trabajadoras, el principio de irradiación de la mayor representatividad.

A la hora de determinar el cómputo de las empresas de la unidad de negociación, habrá que atender "tanto a las que estén afiliadas como tales a una determinada asociación, como a los que pertenezcan a una agrupación integrada a su vez en una organización más compleja» (Roqueta, 2020;6).

La Disposición Adicional 6. ${ }^{a}$ ET otorga la condición de asociación empresarial más representativa a aquella que acredite una implantación significativa en todo el territorio nacional o, en su caso, en el de una Comunidad Autónoma (Roqueta, 2020; 3). Siendo éstas aquellas que en dicho ámbito nacional cuenten con el $10 \%$ o más del total de las empresas, siempre que estas empleen al 10\% o 
más de las personas trabajadoras ${ }^{2}$. Mientras que, serán asociaciones empresariales más representativas a nivel autonómico, las que en tal ámbito cuenten con el $15 \%$ o más de las empresas y estas, a su vez, empleen al 15\% o más de las personas trabajadoras en el ámbito de una determinada Comunidad Autónoma, ańadiendo en este ámbito, el requisito de la no integración de las mismas en una asociación empresarial de ámbito estatal, limitando su actividad, de forma exclusiva, a la Comunidad Autónoma en cuestión. Asimismo, el reparto de la representación de la patronal en la Comisión negociadora se realizará en función de la representatividad de cada una de las asociaciones empresariales.

En los supuestos en los que un convenio colectivo sea pactado «con exclusión de una de las asociaciones empresariales que cuenten con la indicada legitimación básica será estatutariamente nulo»(Roqueta, 2021; 8). Cuestión diferente estriba en los supuestos en los que la asociación empresarial con legitimación inicial se autoexcluya de forma voluntaria, siendo este un derecho renunciable.

De manera que,

la legitimación básica no es suficiente por sí sola para poder negociar un convenio colectivo, por cuanto la capacidad plena requiere una legitimación complementaria que solo la tienen la asociación empresarial, las asociaciones empresariales o las coaliciones de estas» (Roqueta, 2020; 8)

que representen como mínimo a empresarios que ocupen a la mayoría de las personas trabajadoras afectadas por el convenio colectivo.

El TS mediante su sentencia de 11 de noviembre de 2010 , recurso núm. 235/2009, ha estipulado la obligatoriedad de validación de la unidad de negociación creada en la misma no ha de ser de creación artificial, sino que

ha de reunir ciertas características de homogeneidad que permitan establecer una regulación uniforme de las condiciones de trabajo al tiempo que se trate de actividades productivas afines, respondiendo al ámbito elegido a criterios de objetividad y estabilidad (Nieto, 2017; 14).

No obstante, goza de presunción iuris tantum la legitimación de la asociación empresarial firmante del convenio colectivo. Tal presunción «no resulta de aplicación cuando en la fase inicial de constitución de la comisión negociadora se cuestiona la legitimación de las asociaciones empresariales» (Roqueta, 2020; 16). A razón de la obligatoriedad de acreditación por parte de las asociaciones

2 En la actualidad esta condición de asociaciones empresariales más representativas la ostentan la «Conferencia española de Organizaciones empresariales» (CEOE) y la «Confederación Española de Pequeña y Mediana Empresa»(CEPYME). 
empresariales sus respectivos porcentajes de representatividad ex arts. $87.3 \mathrm{c}$ ) y 88.2 ET, en el momento indicado por el legislador.

Debido a lo cual, se ha de considerar que la voluntad del mismo en este extremo fue favorecer o incentivar el desarrollo de la negociación colectiva, dotando de carta de naturaleza legal, y no jurídica, a la legitimación para negociar convenios o acuerdos colectivos en empresas en red en procesos de descentralización productiva. Para lo cual, el legislador optó por una definición de carácter descriptivo y funcional de los rasgos identificadores de la red empresarial (Sanguineti, 2016; 128).

En relación con la representación unitaria, hay que partir de la siguiente premisa; las personas trabajadoras proceden a elegir a sus representantes mediante elecciones en la empresa o centro de trabajo. Dicha premisa, impuesta por el legislador español, dificulta en gran medida la designación de representantes unitarios por parte de las personas trabajadoras de las empresas que componen la red empresarial y que, asimismo, están coordinadas. En virtud de la extensión, o, dicho de otro modo, la limitación del ámbito de representación de esta representación unitaria, no pudiendo extender la misma más allá del centro de trabajo en cual fue elegido. Por lo cual, en ocasiones, aunque con carácter minoritario, en algunos convenios colectivos se ha optado por la creación de un Comité Intercentros, como órgano de participación de las personas trabajadoras integrantes de una red empresarial. Sin embargo, esta organización supraempresarial de la red, además de ser minoritaria, tal y como se ha avanzado con anterioridad, se limita únicamente a regular aspectos derivados de seguridad y salud laboral, con la finalidad última de arbitrar la coordinación de las obligaciones empresariales en tal materia.

Una posible solución a esta disyuntiva sería la de incluir una nueva figura de representación con carácter «informal», para los supuestos de las empresas en red, cuestión que se analizará con posterioridad.

Siguiendo el razonamiento anteriormente expuesto, tampoco se podrá constituir una sección sindical con presencia en la red empresarial. No obstante, el art. 8.1 LOLS abre una vía para la misma a través de la opción de "constituir Secciones Sindicales de conformidad con lo establecido en los Estatutos del sindicato", pudiendo estar disponible para las personas trabajadoras afiliadas a un sindicato, que, siguiendo el procedimiento previsto en el precepto anteriormente referenciado, crean una sección sindical en el "ámbito de empresa o centro de trabajo». Sin embargo, parece poco efectiva la elección de un representante sindical nombrado como portavoz y nexo de unión entre las diferentes secciones sindicales de todas y cada una de las empresas y/o centros de trabajo que conforman la red empresarial.

Empero, no es cuestión baladí el papel primordial de los sindicatos en las empresas en red, pudiendo operar desde fuera de la misma debiendo, no obs- 
tante, adaptarse a la nueva realidad laboral que ha entrado con fuerza en las relaciones laborales y que tiene visión de permanencia. Por otra parte, podría existir una relación de coordinación "no oficial» entre los representantes unitarios y los representantes sindicales de todas las empresas y/o centros de trabajo incluidos en la red empresarial, en mayor medida por iniciativa propia que a razón de las directrices marcadas por el propio sindicato (Díaz, 2018; 240). Pudiendo darse esta coordinación por parte de las personas trabajadoras dejando a un lado, a su vez, a los representantes y sindicatos. Mas esta tercera opción conlleva una mayor dificultad de ejecución que la anteriormente expuesta.

\section{La digitalización de las relaciones laborales como factor de cambio}

La sociedad actual, la sociedad 4.0, derivada de la tercera revolución industrial, se caracteriza por un uso notable de las TICs. Lo cual ha dado lugar a la proliferación de nuevas formas de relaciones laborales basadas en la descentralización y en el uso de dichas tecnologías. A medida que avanza la sociedad, con ella debe hacerlo tanto la normativa, como el funcionamiento de los agentes de tales relaciones laborales. Adecuar la forma de actuar de estos a la nueva realidad social es determinante para la efectividad de los mismos. A razón de lo cual están surgiendo, cada vez más, relaciones laborales con trasfondo digital y un alto índice de temporalidad. Por ello, la necesidad de una modernización de la acción sindical desde la perspectiva digital cobra mayor relevancia.

Aunque se ha dado un avance en materia de políticas de empleo que apuntan a la regulación de condiciones laborales y salariales más justas, así como a la protección social de la persona trabajadora vinculada a través de estas novedosas formas de acceder al empleo, aún falta camino por recorrer.

No podemos dejar sin mencionar la grave crisis económica en la que se ve inmersa no solo Espańa sino todos los países derivada de la pandemia, ya que ésta ha puesto de manifiesto la importancia de la concienciación acerca de la necesidad de afrontar el impacto de la digitalización en las relaciones laborales, pues debido a dicha situación se ha evidenciado la importancia del uso de las TICs, además de la necesidad de adaptación por parte de las empresas a estos medios, para lograr mayor competitividad en el mercado.

Así, la economía digital y el uso de las TICs han dado un giro de $180^{\circ}$ a la proyección de las actividades productivas: desde la manera en que se produce la información, informes, planes de trabajo, metas, resultados, entre otros, a través de herramientas digitales, tales como el ordenador, la tableta o incluso el móvil, hasta la forma en que se visualiza o se observa tal información.

La concepción clásica de persona trabajadora se venía articulando a través de las nociones de dependencia y ajenidad. Ha de anotarse que dichas nociones 
forman parte de las denominadas notas de laboralidad contenidas en el ET, y las cuales son determinantes para denotar si estamos ante una relación de laboralidad, es decir, ante una persona trabajadora por cuenta ajena o ante una persona trabajadora por cuenta propia. La temporalidad, junto a la alta tasa de rotación de los empleos, entre otras cuestiones, dan lugar a una huida por parte del tejido empresarial de la aplicación de la norma. Además, los trabajos realizados a través de plataformas digitales, conllevan una notable incertidumbre, inestabilidad y precariedad (Mercader, 2020; 5). De manera que estas nuevas formas económicas y de prestación de servicios han de encontrar su encaje en la normativa laboral actual.

En consecuencia, el legislador español ha optado por una regulación para las personas trabajadoras que realizan su prestación de servicios a través de plataformas digitales, en vez de adecuar la ya existente con una nueva interpretación de los preceptos ya contenidos en el ET y demás normas coordinantes. Razón por la cual el pasado 12 de mayo de 2021 se publicó el Real Decreto-Ley 9/2021, de 11 de mayo, por el que se modifica el texto refundido de la Ley del Estatuto de los Trabajadores, aprobado por el Real Decreto Legislativo 2/2015, de 23 de octubre, para garantizar los derechos laborales de las personas dedicadas al reparto en el ámbito de plataformas digitales. En dicha norma se produce la modificación del art. 64.4 d) ET y la introducción de la Disposición Adicional Vigesimotercera, teniendo como fecha de entrada en vigor el 12 agosto del corriente — tres meses posteriores a su publicación-.

Asimismo, se dota a la representación de las personas trabajadoras del derecho a la información, consulta y participación relativo a

los parámetros, reglas e instrucciones en los que se basan los algoritmos o sistemas de inteligencia artificial que afectan a la toma de decisiones que pueden incidir en las condiciones de trabajo, el acceso y mantenimiento del empleo, incluida la elaboración de perfiles.

Empero el precepto de mayor transcendencia es la Disposición Adicional Vigesimotercera, por la cual, se dota de presunción iuris tantum al carácter de laboralidad de la prestación de servicios a través de plataformas digitales. Dejando zanjado, por ende, el debate jurisprudencial sobre tales extremos acaecidos en los últimos años en cuanto a la laboralidad o la falta de ella de estas personas trabajadoras a través de plataformas digitales. Aun siendo el debate de una importante transcendencia, las siguientes líneas se centrarán en la primera cuestión dada su relación estrecha con las mismas.

En virtud de lo cual, mediante de la nueva redacción del art. 64.4 d) ET, el legislador nacional ha intentado suplir esas limitaciones o deficiencias aplicativas del derecho a libertad sindical, en este caso a través de las limitaciones en el ejercicio de sus funciones de los representantes legales de las personas 
trabajadoras, dotándolas de un derecho a la información en relación a los algoritmos o sistemas de inteligencia artificial que afectan a la toma de decisiones, parámetros, reglas e instrucciones de los empleadores que están detrás de las plataformas digitales. Cuestión esta última no baladí, ya que en ocasiones es compleja su determinación. En este sentido es importante traer a colación lo que entiende De la Villa en relación con el concepto de empleador, "es un concepto traslativo que se perfila indirectamente por remisión a la persona del trabajador, pues empleador será todo aquel que ocupa a otro como trabajador» $(2010 ; 13-41)$.

Esto constituye un paso más hacia el refuerzo de los derechos de las personas trabajadoras en plataformas digitales, quedando todavía mucho camino por recorrer. Pudiendo ir más allá, tal y como entiende Mercader, estableciendo el concepto de «empresa tecnológicamente responsable», con la finalidad última, tal y como expresa el autor, de poner «diques de contención al irrefrenable cambio tecnológico que pasa por la plena concienciación de todos los agentes sociales, económicos y políticos sobre los devastadores efectos del tsunami tecnológico» (Mercader, 2020; 14).

En los supuestos en los que las redes de empresas operen a través de una plataforma, las personas trabajadoras de la misma se encuentran más distanciadas, llegando hasta el extremo de no conocer a otra persona trabajadora de la red, por lo cual «deviene casi imposible crear relaciones de confianza suficientes como para elegir delegados» (Álvarez; 2017, 157).

En virtud de lo cual, la organización de la acción sindical a través de plataformas sindicales cada vez cobra una mayor relevancia en la sociedad 4.0 actual, en la que el uso de las TICs se ha hecho un importante hueco en las relaciones laborales, tanto por la organización de la prestación de servicios, como la contratación de las personas trabajadoras, entre otras cuestiones, dando un vuelco a la concepción clásica de las relaciones laborales. De manera que, los sindicatos pueden servirse de las TICs tanto para realizar funciones de captación, información y formación a sus afiliados, como para aumentar su eficiencia en las funciones de organización y acción sindical, lo cual se encuentra íntimamente ligado con la economía corporativa. De manera que, la acción digital a través de medios digitales "permitiría una presencia sindical cercana al trabajador» (Díaz, 2019; 347), como por ejemplo, a través del voto telemático en las elecciones a representantes de las personas trabajadoras, aunque con la obligación del aseguramiento de la «intervención de forma simultánea de todos los miembros de la comisión negociadora» ${ }^{3}$.

3 Tal y como establece la Audiencia Nacional en su sentencia de 3 de marzo de 2016, recurso núm. 384/2015. Posteriormente confirmada por el Tribunal Supremo en sentencia de 21 de abril de 2017, recurso núm. 149/2016). 
En consecuencia, tanto el Título II como el Título III ET han de ser releídos en virtud de estas nuevas realidades laborales, ya que éstas suponen una disminución de efectividad del derecho a la acción colectiva.

\section{Ordenación negociadora en redes empresariales}

La ruptura de la concepción clásica de empresa, en unidades separadas con grupos autónomos de trabajo, provocada por la deslocalización empresarial, ha generado una desunión de los intereses de las personas trabajadoras de la empresa en red. En consecuencia, las organizaciones sindicales se encuentran con unas dificultades notables para poder acercarse a todos y cada uno de los intereses de dichas personas trabajadoras, limitando, con ello, su fuerza como sindicato más representativo y todos los derechos aparejados por tal condición.

El desplazamiento del poder de dirección que lleva aparejadas las relaciones de las empresas en red, altera de forma notable la bilateralidad contractual característica del contrato de trabajo (Soler, 2021; 17).

En cuanto al capital humano, habrá que distinguir, por un lado, a aquellas personas trabajadoras que han sido contratadas por la red y que realizan su prestación de servicios, únicamente a favor de esta. Por otro lado, estarían aquellas personas trabajadoras que realizan su prestación de servicios solamente para empresas incluidas en la red pero que no desarrollan su actividad para ésta. Y en último lugar, nos encontramos con aquellas personas trabajadoras que, siendo contratadas por una empresa perteneciente a su red, su prestación de servicios se desempeńa tanto para la empresa contratante como para la red empresarial (Soler, 2021; 19). Este último supuesto será el más complejo a la hora de determinar el convenio colectivo aplicable.

En relación a la anterior clasificación podemos establecer tres escenarios posibles en los que nos podemos encontrar a la hora de analizar una empresa red. En el primero de ellos se aplicaría el convenio colectivo de la empresa contratante, mientras que, en el segundo, la persona trabajadora estaría sujeta al convenio colectivo de la red durante el tiempo de prestación de servicios a esta y, en su defecto, se debería acudir al convenio colectivo aplicable en la empresa contratante, así como, en el último supuesto sería más recomendable la aplicación sucesiva de los convenios colectivos en función de en qué empresa esté desarrollando su prestación de servicios.

No obstante, la aplicación del convenio colectivo de red a personas trabajadoras no contratadas por la misma y que presten sus servicios para ella generaría graves controversias en su aplicación. Por lo cual, para salvar dichas controversias podemos acudir a la aplicación analógica del supuesto de la prestación de servicios de las personas trabajadoras en las empresas de trabajo temporal. 
En virtud del artículo 11 de la Ley 14/1994, de empresas de trabajo temporal, se extienden las condiciones de trabajo esenciales a las personas trabajadoras contratadas por la empresa de trabajo temporal que presten servicios en la empresa usuaria, en relación a la remuneración, duración de la jornada, horas extraordinarias, periodos de descanso, trabajo nocturno, vacaciones y días festivos, que ostenten las personas trabajadoras contratadas directamente por la empresa usuaria. Sin embargo, esta opción conlleva efectos negativos como la falta de normativa regulatoria o la «indicación que esas nuevas condiciones aplicables deberían ser más favorables para el trabajador» (Soler, 2021; 20), que las ofrecidas por la empresa contratante.

De manera que, en función de la aplicación del convenio colectivo en las empresas red se atisbarán unas mayores o menores diferencias. Siendo así, en los supuestos en los que hubiera un convenio colectivo aplicable único a todas las empresas de la red, las diferencias entre las condiciones de trabajo de las personas trabajadoras de la empresa red serán consustancialmente inferiores en relación a los supuestos en los que dicho convenio colectivo aplicable no es único, sino que hubiera varios convenios de aplicación en función de la directa contratación, por cada empresa que forma parte de la red, de las personas trabajadoras que, finalmente, realizan su prestación de servicios a favor de la red empresarial.

Asimismo, se ha de poner en relación lo anteriormente expuesto, con la existencia de otra posibilidad, siendo esta la extensión del convenio colectivo de la red horizontal a las personas trabajadoras desplazadas.

La homogeneización de las condiciones laborales en todas las empresas vinculadas dotaría de grandes beneficios tanto a las personas trabajadoras, como a las empresas de la red. Dicha homogeneización podría materializarse en un acuerdo colectivo.

Tal convenio colectivo de empresas en red lleva consigo la posibilidad de una reorganización empresarial en aquellos supuestos en los que se ha producido una previa externalización (Soler, 2021; 22). De manera que, con la creación de tal convenio o acuerdo colectivo no solamente se verá fortalecida la capacidad sindical y la fuerza de las personas trabajadoras, sino que la empresa podrá obtener una serie de ventajas con el mismo, tales como la reordenación de elementos logísticos, de coste, de factores productivos, de duplicidades, etc., así como, ventajas de carácter competitivo ${ }^{4}$.

En cuanto al contenido de los mismos, este dependerá del grado de cohesión que se quiera adoptar por la agrupación (Soler, 2021; 23), pudiendo verse

\footnotetext{
${ }^{4}$ En el mismo sentido se expresa Sanguineti al entender que "puede representar un instrumento útil para que sus integrantes satisfagan necesidades comunes vinculadas con el desarrollo de la colaboración» $(2016 ; 74)$.
} 
limitado su ámbito personal de aplicación a las personas trabajadoras que llevan a cabo tareas específicas y directamente relacionadas con la colaboración existente entre tales empresas, o también, en cuanto a las relaciones de trabajo a fin de homogenizar las mismas para todas las personas trabajadoras que desarrollen funciones específicas vinculadas con dicha colaboración. Rigiendo, a su vez, con carácter supletorio, lo estipulado en el convenio colectivo sectorial o de empresa que le sea de aplicación.

El Acuerdo de 15 de marzo de 2016 entre Repsol y CCOO en relación a la implementación de medidas de seguridad y salud de las personas trabajadoras, da un paso en la ordenación de las obligaciones en materia de seguridad y salud laboral en las empresas de la red. No obstante, dicho acuerdo se centra en mayor medida en la protección de la seguridad y salud de las empresas auxiliares que operan en los complejos industriales de Repsol petróleo (Soler, 2021; 24).

De manera que, el convenio colectivo de empresa o de sector,

se constituirá como garante de mínimos para los trabajadores desplazados, así como reguladores de condiciones exclusivas de su ámbito, mientras que este convenio «vinculado» garantiza las especificidades que el desarrollo de la actividad requiere en el entorno de la red (Soler, 2021; 25).

Siendo notoria la necesidad de una reestructuración de la concepción clásica de los sindicatos en cuanto a la forma a llevar acabo sus funciones y competencias, como a las manifestaciones de la autonomía colectiva no solo ad extra, sino, también, ad intra.

\subsection{Unión temporal de empresa (UTE)}

La UTE, entendida como aquella agrupación de empresas surgida con el fin último de alcanzar un objetivo de naturaleza jurídica, se verá extinguida en el momento de la finalización de dicha relación jurídica, o más concretamente, negocio jurídico, por el cual se procedió a la mera unión temporal (Martín, 2020; 139).

En relación a las personas trabajadoras que realizan su prestación de servicios enmarcadas dentro de una UTE, podemos llevar a cabo la siguiente clasificación; en un primer lugar, la UTE puede contratar ex novo a parte o a la totalidad de la plantilla, en su propio nombre; en segundo lugar, la UTE se puede servir de las personas trabajadoras de las empresas agrupadas ${ }^{5}$, de manera que, tal realización de su prestación de servicios se realiza en favor de la UTE, situándose, por ende, dentro de su ámbito de organización y dirección por el tiempo necesario para la satisfacción de su objeto; y, en tercer lugar, que la UTE no establezca un ámbito de organización y control diferenciado de las empresas inte-

5 STSJ Castilla y León, Valladolid, 7 mayo de 2014, entre otras. 
grantes de la misma, sino que únicamente las personas trabajadoras que ejercen su prestación de servicios en la misma lo hacen bajo la dirección y control de la empresa integrante de la UTE y por la cual fue contratada, a través del reparto y desarrollo independiente de las actividades por parte de las empresas integrantes de la UTE.

Acorde con la primera de las vías anteriormente mencionadas, la determinación de las condiciones de trabajo de las personas trabajadoras afectadas por la misma será la del convenio colectivo aplicable, siendo este el de las UTE o, en su defecto, el del sector (Solís, 2018; 85). Recayendo, por ende, el incumplimiento del mismo en responsabilidad solidaria e ilimitada de todas las empresas integrantes de la UTE.

Por otro lado, la contratación expresa para prestar servicios en la UTE puede considerarse cesión legal de las personas trabajadoras. En tanto que las mismas realizan su prestación de servicios a favor de las UTE como si se tratara esta de una empresa usuaria, mientras que la facultad sancionadora recaería sobre la empresa contratante (Solís, 2018; 88). No obstante, en los supuestos en los que las personas trabajadoras realicen su prestación de servicios en ambas empresas, empresa contratante y UTE, se tornará más dificultoso su encuadramiento normativo.

Mientras que, en los supuestos en los cuales se repartan las actividades y desarrollen de forma independiente las mismas por parte las empresas miembros de la UTE, se puede dar el caso de que se establezcan en sus estatutos las prestaciones a realizar por cada una de las empresas que las conforman (Solís, 2018; 92).

En consecuencia, la regulación de la actividad de las UTE se encuentra bajo una laguna normativa y, por ende, de una inseguridad jurídica manifiesta. Por lo cual, es importante traer a colación la relevancia de no perder de vista la diferenciación de las UTE y del grupo de empresas, no siendo iguales ambas construcciones jurídicas.

Por otro lado, puede darse el supuesto en el que la UTE, a su vez, se encuentre inmersa en una red empresarial. En función de lo cual, ha de traerse a colación que en la estructura de la negociación en redes verticales, «las condiciones laborales serán diferenciadas en función de la adscripción a una empresa determinada, pese a que la actividad se realice por una misma red» (Soler, 2021; 27). La heterogeneidad dimanada de esta red vertical se podría ver resuelta a través de un acuerdo colectivo que eliminara o, en su defecto, mitigara en la medida de lo posible tal condición. Empero, tal posibilidad se entronca compleja en cuanto a su negociación, debido a la disparidad de posiciones e intereses.

En las empresas red verticales, se concentra un elevado nivel de precariedad y rotación en el empleo (Sanguineti, 2016; 69), lo cual conlleva a la enorme di- 
ficultad de poder realizar su ejercicio a afiliación. Asimismo, supone un alto costo para las organizaciones sindicales incentivar su presencia en este tipo de estructuras empresariales.

Uno de los puntos clave para desarrollar la negociación colectiva en empresas vinculadas será la determinación de la unidad de negociación necesaria para la consecución del acuerdo colectivo. Siendo requisito necesario para la configuración de la misma la voluntad negocial de las partes.

Sin embargo, no existen fórmulas de promoción como espacio de negociación, lo que da lugar a la existencia residual de tales convenios o acuerdos colectivos en empresas vinculadas. Siendo una tarea pendiente del legislador la creación de una normativa que regule tal promoción, ampliando, con ello, los espacios de negociación a estas nuevas unidades.

La persona trabajadora desplazada o en misión presenta similitudes con la persona trabajadora que realiza su prestación de servicios a en la empresa subcontratada, por lo cual, se podrían extrapolar algunos parámetros de la regulación en esta materia, así como en lo concerniente a diversos elementos de la regulación de las empresas de trabajo temporal, a las empresas vinculadas verticalmente.

Por su parte, los Acuerdos Marco Internacionales o Globales negociados entre empresas multinacionales y sindicatos internacionales y locales, y dotados de dimensión transnacional, se consideran instrumentos adecuados, tanto para la OCD como para la OIT, para dotar de un mayor empaque a los procesos de debida diligencia empresarial en la cadena de suministro, «creando así una relación de confianza entre los diferentes interesados» (Rojas, 2019; 365). De manera, a través de estos Acuerdos Marco Internacionales o Globales las empresas multinacionales que lo suscriben irradian su contenido a las otras entidades mercantiles unidas a esta, tales como proveedores, suministradores, empresas asociadas, empresas participadas, y cualquier otra mercantil integrante de su cadena valor. A razón de la posición de prevalencia e irradiación de su influencia de las primeras frente a las segundas.

En contraposición a lo entendido por Sanguineti, el cual sostiene que

no parece representar una opción muy viable debido a las evidentes diferencias, no solo los muy variados tipos de redes que pueden existir, sino entre las actividades, posiciones e intereses de las empresas que las componen (2016; 72).

Empero, considera, a su vez, el enorme potencial regulador del convenio colectivo de empresa en red como mecanismo regulador de los fenómenos de desarticulación empresarial $(2016 ; 17)$. Ya que, este debilitamiento de los convenios colectivos de empresa lleva aparejado un debilitamiento de las unidades de negociación (Sanguineti, 2016; 71). Todo ello diamante, a su vez, de las dificul- 
tades de los interlocutores sociales en las empresas en red, así como, a la cada vez más reducida presencia sindical. No obstante, en estos supuestos el convenio colectivo resulta ineficaz, debido a que el proceso productivo se fragmenta y, con ello, el poder de dirección en una pluralidad de sujetos con personalidad diferenciada (Sanguineti, 2016; 70).

Por otro lado, en relación con los convenios colectivos aplicables a un grupo de empresas o a empresas vinculadas, el art. 84.2 ET establece la misma prioridad aplicativa que el convenio de empresa, pudiendo, por ende, llevarse a cabo la promoción de su negociación por parte de los sujetos legitimados en cualquier momento, aunque estén en vigor uno o varios convenios sectoriales. Por ello, no se contempla la posible concurrencia de los convenios del grupo y los convenios propios de cada una de las empresas de la red (Rojas, 2018; 269).

Ejemplos en este sentido encontramos: el convenio colectivo de Ombuds Servicios, SL, Protección Castellana, SLU y UTE Thyssen ${ }^{6}$; el convenio colectivo de Bolsas y Mercados Espańoles ${ }^{7}$; el convenio colectivo de las empresas Fomento de Construcciones y Contratas, S. A., UTE RM2 y UTE Recogida Sur Madrid $^{8}$, entre otros.

\subsection{Empresas multiservicios y negociación colectiva}

La función de las cláusulas de subrogación convencional es

evitar que la continuidad de los contratos, en sectores fuertemente expuestos a la subcontratación, quede al albur de la voluntad del nuevo contratista, imponiéndole la obligatoria subrogación de los contratos de todos o parte de los trabajadores empleados por el anterior titular de la contrata (Nieto, 2017; 4).

La inexistente regulación normativa en este aspecto conlleva a que la negociación colectiva posea una posición privilegiada en aquellos sectores afectados de forma notable por la competencia realizada por las empresas multiservicios. De manera que, cuando las empresas multiservicios realizan funciones de subcontratación, las empresas principales se benefician de las insuficiencias o, mejor dicho, deficiencias de la normativa aplicable a esta tipología de empresas, así como de la interpretación judicial dada a las mismas en relación con su diferente

6 Resolución de 29 de junio de 2018, de la Dirección General de Trabajo, por la que se registra y publica el Convenio colectivo de Ombuds Servicios, SL, Protección Castellana, SLU y UTE Thyssen (BOE núm. 167, de 11 de junio de 2018).

7 Resolución de 8 de enero de 2019, de la Dirección General de Trabajo, por la que se registra y publica el Convenio colectivo de Bolsas y Mercados Españoles (BOE núm. 20, de 23 de enero de 2019).

8 Resolución de 9 de octubre de 2019, de la Dirección General de Trabajo de la Consejería de Economía, Empleo y Competitividad, sobre registro, depósito y publicación del convenio colectivo de las empresas Fomento de Construcciones y Contratas, S. A., UTE RM2 y UTE Recogida Sur Madrid. (BOCM núm. 297, de 14 de diciembre de 2019). 
casuística, mayoritariamente restrictiva de los preceptos garantistas que la integran (Monereo, 2018; 403). Además de la interpretación cada vez más amplia de la casuística procedente para la realización de extinciones por voluntad unilateral del empresario en supuestos de descentralización productiva y externalización de la producción y/o los servicios (Esteve, 2018; 438).

No obstante, tanto las empresas multiservicios como las empresas principales se encuentran obligadas a soportar lo contenido en los arts. 42 ET, 24.3 LPRL y 42.3 LISOS, así como la demás normativa aplicable. Recayendo sobre ellos, por ende, la responsabilidad subsidiaria por cotizaciones no abonadas a la Seguridad Social, además de las prestaciones que corresponden a los contratistas y subcontratistas por incumplimiento de las obligaciones de afiliación, alta o cotización a la Seguridad Social; y, las obligaciones de coordinación preventiva ex art. 24 LPRL. Sin embargo, las empresas multiservicios no tienen la condición de propia actividad contenida en el art. 42 ET.

En la práctica, las empresas multiservicios evaden la aplicación de los convenios colectivos sectoriales específicos aplicables para sectores concretos de la actividad, siguiendo el principio de preferencia legal de los convenios de empresa (Monereo, 2018; 408). Lo cual les permite, tanto a las empresas multiservicios como a las empresas que las contratan, disminuir el precio de mercado a razón del bajo coste laboral, ya que el monto a pagar a la mano de obra es inferior en relación a lo estipulado en el convenio colectivo de sector, dando lugar, a su vez, a una clara competencia desleal de ambas mercantiles. A lo que hay que añadir la existencia de una mayor vulnerabilidad en relación con la vinculación entre la persona trabajadora y la empresa subcontratista o la empresa auxiliar (Martín, 2020; 26).

El legislador nacional, de forma alarmante, ha incentivado estas prácticas con la reforma del art. $84 \mathrm{ET}$, al dar prioridad aplicativa al convenio de empresa sobre el convenio colectivo sectorial.

En este sentido, el convenio colectivo negociado en Adecco Outsourcing S.A.U. y en Atlas Servicios Empresariales, S.A.U. ${ }^{9}$, tiene como objetivos respectar el convenio colectivo sectorial, así como regular las condiciones de trabajo en otras actividades sin convenio colectivo de aplicación (Esteve, 2018; 447). Dando un giro de $180^{\circ}$ a la voluntad del legislador de 2012 , de manera que, mediante lo contenido en el mismo, se da prioridad a lo estipulado en el convenio colectivo, en detrimento del contenido en el convenio colectivo de empresa. En consecuencia, este último tendrá una aplicación subsidiaria en relación con las estipulaciones del convenio colectivo sectorial. En contraposición con lo ex-

\footnotetext{
9 Resolución de 16 de junio de 2017, de la Dirección General de Empleo, por la que se registra y publica el Convenio colectivo de pluralidad de empresas vinculadas por razones organizativas: Atlas Servicios Empresariales, SAU y Adecco Outsourcing, SAU. (BOE núm. 158, de 4 de julio de 2017).
} 
puesto en el convenio colectivo de acciona multiservicios ${ }^{10}$ y el convenio colectivo de Clece Servicios Auxiliares ${ }^{11}$, por todos. En este extremo es relevante traer a colación lo acaecido en relación con los convenios colectivos negociados por Adecco Outsourcing con anterioridad, al no haber sido negociado por representantes de todos los centros de trabajo.

Como segundo instrumento encontramos las cláusulas de equiparación de las condiciones económicas y sociales de las personas trabajadoras de las contratas con las de la plantilla de la empresa principal.

No obstante, algunos convenios colectivos sectoriales establecen prohibiciones o limitaciones a la externalización de actividades. Las prohibiciones absolutas incondicionales han de considerarse ilegales al vulnerar el derecho a la libertad de empresa (Esteve, 2018; 443).

Otra opción, la encontramos en la inclusión de las empresas multiservicios en el ámbito funcional de un convenio colectivo sectorial. Sin embargo, la aplicación de esta trae como consecuencia una serie de controversias, sobre la «legalidad de esta integración a la luz de la integridad de los firmantes en desde el banco patronal y su capacidad para vincular empresas multiservicios» ${ }^{12}$ (Esteve, 2018; 443).

En cuanto al banco social, su conformación debe regirse por los criterios establecidos para la negociación de los convenios colectivos de ámbito sectorial, esto es, los sindicatos más representativos. En virtud de lo cual, podemos observar que en la negociación de los convenios colectivos de las empresas en red no ostentará legitimación inicial ni negocial, la representación unitaria o sindical de las personas directamente afectadas por el mismo, ni la posible comisión ad hoc de las propias personas trabajadoras.

Sin embargo, se ha de señalar que el artículo 87.1 párrafo 3. ${ }^{\circ}$ ET dispone una serie de singularidades en supuestos de unidades complejas, en relación con lo establecido en el articulado de forma originaria. De manera que el reenvío directo del art. 87.1, párrafo $3 .^{\circ}$ et al. artículo 87.2 de mismo cuerpo legal, nos indica que la atribución negociar la ostentan tres grupos de sujetos, todos con naturaleza sindical: sindicatos que tengan la consideración de más representativos a nivel estatal, así como las organizaciones afiliadas, federadas o confederadas a

10 Resolución de 8 de octubre de 2013, de la Dirección General de Empleo, por la que se registra y publica el Convenio colectivo de Acciona Multiservicios, SA. (BOE núm. 250, de 18 de octubre de 2013).

11 Resolución de 11 de junio de 2013, de la Dirección General de Empleo, por la que se registra y publica el II Convenio colectivo de Clece, SA (servicios auxiliares) (BOE núm. 153, de 27 de junio de 2013)

12 Diferente consideración ha tenido las unidades de negociación en los grupos de empresas, viendo su legitimación concretada por la jurisprudencia del Alto Tribunal. 
estos, en sus respectivos ámbitos; los sindicatos más representativos a nivel de Comunidad Autónoma, así como las organizaciones afiliadas, federadas o confederadas a ellos, también en sus respectivos ámbitos; y, los sindicatos que, sin encuadrarse en ninguno de los supuestos anteriores, cuenten con al menos el 10\% de los representantes unitarios de los representantes de las personas trabajadoras en el ámbito de convenio.

En los supuestos en los que la empresa carezca de convenio colectivo aplicable, el TS ha establecido a través de sus sucesivas resoluciones cual ha de ser el convenio colectivo aplicable, siendo estos: 1) aplicar el convenio que corresponda a la actividad principal o preponderante de la empresa multiservicios; 2) aplicar el convenio de la empresa principal o cliente; 3 ) aplicar el convenio sectorial que corresponda a la actividad objeto de la contrata (Martín, 2020; 67).

A raíz de la notable diferencia de poder en las relaciones laborales entre una persona trabajadora y empresa multiservicios, mucho mayor que entre una empresa no multiservicios y la propia persona trabajadora, el legislador debe compensar la misma. Optando por aplicar un principio básico de la legislación laboral de forma análoga, el principio de condición más beneficiosa. Siendo su fin último que en los casos en los que entre en conflicto que convenio colectivo le es de aplicación a una persona trabajadora de una empresa multiservicios, se aplicaría el más beneficioso para dicha persona trabajadora. Compensando de esta forma el desequilibrio flagrante de las partes en dicha relación laboral (Martín, 2020; 69).

\section{Conclusiones}

I.- El imprescindible papel del convenio colectivo como mecanismo armonizador y ordenador de las relaciones laborales, ha de ser cuidado y mantenido tanto por el legislador laboral como por los agentes sociales y por las partes de la relación laboral -empresa y representantes de las personas trabajadoras-. Ya que actualmente la misma no es efectiva ni eficiente para el conjunto de las nuevas formas de relaciones laborales, tendiendo estas, visos de ser predominantes. Por lo que se deberá posibilitar e incentivar una cultura de red, tanto a empresas como a personas trabajadoras, para lograr una efectiva acción colectiva y, por extensión, una eficacia mayor del derecho a la libertad sindical en su conjunto.

II.- Surge la imperiosa necesidad de reformular de forma íntegra lo contenido por el legislador en el art. $42 \mathrm{ET}$, con la finalidad de dotar de unos mayores instrumentos para garantizar los derechos de las personas trabajadoras, a lo que la negociación colectiva tal y como se entiende en la actualidad, no ha podido llegar. 
III.- En relación con la representatividad empresarial y sindical en las empresas red -y sobre todo cuando existe el tinte de transnacionalidad-, nos lleva a una propuesta de lege ferenda al legislador en relación a la modificación del Título III del ET a la hora de dar legitimación negocial a los representantes.

\section{Bibliografía}

Álvarez Cuesta, Henar (2017), El futuro del trabajo vs. El trabajo del futuro. Implicaciones laborales de la Industria 4.0, A Coruña, Colex.

De la Villa, Luis Enrique (2010), «El concepto de empresario-empleador en el Derecho del Trabajo», Blasco Pellicer, A (coordinador), El empresario laboral, Valencia, Tirant Lo Blanch.

DíAz Rodríguez, Juan Miguel (2018), «Acción sindical en las redes empresariales», Sanguineti Raymond, Wilfredo y Vivero Serrano, Juan Bautista (dir.), Impacto de las redes empresariales, Granada, Comares.

DíAz Rodríguez, Juan Miguel (2019), «La innovación tecnológica en la acción sindical ante las nuevas realidades empresariales», Sanguineti Raymond, Wilfredo y Vivero Serrano, Juan Bautista (dir.), La Construcción del Derecho del Trabajo de las redes empresariales, Granada, Comares.

Esteve Segarra, Amparo (2018), «La negociación colectiva de las empresas vinculadas en el marco de las redes empresariales integradas por las empresas multiservicios», Sanguineti Raymond, Wilfredo y Vivero Serrano, Juan Bautista (dir.), Impacto de las redes empresariales, Granada, Comares.

Krebs, Perter y Jung, Stefanie (2017), «Estructura de gobernanza en redes empresariales», en Ruiz Peris, Juan Ignacio (dir.), Claves del derecho de redes empresariales, Valencia, Universitat de Valencia, 127-169.

Martín Vales, Priscila (2020), Análisis jurisprudencial en los supuestos de subcontratación, A Coruña, Colex.

Mercader Uguina, Jesús, R. (2020), «Nuevos escenarios para el Estatuto de los Trabajadores del siglo xxI: digitalización y cambio tecnológico», Trabajo y derecho, 63.

Monereo Pérez, José Luis (2018), "El empleador plural en las empresas multiservicios», Sanguineti Raymond, Wilfredo y Vivero Serrano, Juan Bautista (dir.), Impacto de las redes empresariales, Granada, Comares.

Nieto Rojas, Patricia (2017), «La respuesta de la negociación colectiva sectorial a las empresas multiservicios", Revista de Información Laboral, 7.

Rojas Rivero, Gloria P. (2018), "La negociación colectiva en las redes empresariales», Sanguineti Raymond, Wilfredo y Vivero Serrano, Juan Bautista (dir.), Impacto de las redes empresariales, Granada, Comares.

Rojas Rivero, Gloria P. (2019), "La negociación colectiva ante las nuevas formas de trabajar», Sanguineti Raymond, Wilfredo y Vivero Serrano, Juan Bautista (dir.), La Construcción del Derecho del Trabajo de las redes empresariales, Granada, Comares.

Roqueta BuJ, Remedios (2020) «Representatividad empresarial y negociación colectiva sectorial», Revista Española de Derecho del Trabajo, 229.

Ruiz Peris, Juan Ignacio (2018), «Las redes empresariales como fenómeno económico y realidad jurídica», Sanguineti Raymond, Wilfredo y Vivero Serrano, Juan Bautista (dir.), Impacto de las redes empresariales, Granada, Comares. 
Sanguineti Raymond, Wilfredo (2016), Redes empresariales y Derecho del Trabajo, Granada, Comares.

Solís Prieto, Carmen (2018), «Uniones Temporales de Empresas: implicaciones de un fenómeno de cooperación interempresarial carente de regulación en el ámbito laboral», Sanguineti Raymond, Wilfredo y Vivero Serrano, Juan Bautista (dir.), Impacto de las redes empresariales, Granada, Comares.

Soler Arrevola, José A., (2021), "Reflexiones sobre la negociación colectiva en las redes empresariales verticales y horizontales", Revista Española de las Relaciones Laborales, 238. 